\title{
PERANCANGAN KENDALI SUHU PADA PURWARUPA PENGERING PAKAN IKAN MENGGUNAKAN METODE KONTROL PI BERBASIS MIKROKONTROLER
}

\author{
Achmad Jaelani*), Aris Triwiyatno, dan Sudjadi \\ Departemen Teknik Elektro, Universitas Diponegoro \\ Jl. Prof. Sudharto, SH, Kampus UNDIP Tembalang, Semarang 50275, Indonesia \\ ${ }^{*}$ E-mail:jeeielan@gmail.com
}

\begin{abstract}
Abstrak
Metode kontrol yang digunakan pada alat pengeringan pakan ikan di Lab FPIK (Fakultas Perikanan dan ilmu Kelautan) Universitas Diponegoro ini masih menggunakan metode kontrol On-off yang kurang efektif serta pengendalian suhu masih menghasilkan keluaran yang tidak stabil dan susah untuk mencapai referensi suhu yang diinginkan terlebih jika mendapat gangguan. Oleh karena itu, dibutuhkan metode kontrol yang baik untuk menangani permasalahan kurang efektifnya metode kontrol pada alat pengering pakan ikan di Lab FPIK UNDIP. Pada penelitian ini dirancang kendali suhu pada purwarupa pengering pakan ikan menggunakan sensor DHT22 dan sensor SEN0193, mikrokontroler Atmega328P sebagai otak pengendalian utama, modul bluetooth HC-05 sebagai media komunikasi antara mikrokontroler dengan interface. Metode kontrol yang digunakan untuk mengendalikan suhu pada purwarupa pengering pakan ikan adalah PI (Proporsional Integral). Parameter kontrol PI diperoleh melalui metode tuning Ziegler Nichols 1 dengan nilai $\mathrm{Kp}=18,4$ dan $\mathrm{Ti}=133,2$. Hasil pengujian metode kontrol PI terhadap tiga variasi referensi suhu $55^{\circ} \mathrm{C}, 57^{\circ} \mathrm{C}$, dan $53^{\circ} \mathrm{C}$ serta pemberian gangguan pada referensi suhu $55^{\circ} \mathrm{C}$, yaitu mampu menghasilkan respons sistem yang stabil meskipun masih berosilasi.
\end{abstract}

Kata Kunci: purwarupa pengering pakan ikan, Sensor suhu DHT22, mikrokontroler Atmega328P, Metode kontrol PI

\begin{abstract}
The control method used for the fish feed dryer in the FPIK Lab (Faculty of Fisheries and Marine Sciences) of Diponegoro University still uses the less effective On-off control method and temperature control still produces unstable and difficult outputs to achieve the desired temperature reference, especially when you get interferenced. Therefore, a good control method is needed to deal with ineffectiveness problem of the control method on the fish feed dryer in the FPIK UNDIP Lab. This project design the temperature control on the fish feed dryer prototype using DHT22 sensor and SEN0193 sensor, Atmega328P microcontroller as the main control brain, HC-05 bluetooth module as communication media between microcontroller and interface. The fish feed dryer prototype uses PI (Proportional Integral) as its control method for temperature control. The parameters of the PI control were obtained through Ziegler Nichols 1 tuning method with $\mathrm{Kp}=18.4$ and $\mathrm{Ti}=133.2$. The PI control method have been tested using three various temperature references which are $55^{\circ} \mathrm{C}, 57^{\circ} \mathrm{C}$, and $53^{\circ} \mathrm{C}$ with adding interference to the $55^{\circ} \mathrm{C}$ temperature reference. Throughout the test, The PI control method is able to produce a stable system response even though it is still oscillating.
\end{abstract}

Keywords: Fish feed drier prototype, DHT22 Sensor, Microcontroller Atmega328P, PI control method.

\section{Pendahuluan}

Pengendalian suhu di industri perikanan kini semakin berkembang pesat pada era modern sekarang ini sehingga dibutuhkan pengendalian suhu yang stabil agar menghasilkan respons sistem sesuai dengan referensi, akan tetapi masih banyak pengendalian suhu di industri perikanan yang kurang stabil dalam pengendalian suhunya, salah satunya pada kasus pengendalian suhu di alat pengering pakan ikan yang berlokasi di laboratorium
FPIK (Fakultas Perikanan dan Ilmu Kelautan) Universitas Diponegoro. Metode kontrol yang digunakan pada alat pengering pakan ikan di Laboratorium FPIK ini masih menggunakan metode kontrol On-off yang kurang efektif, serta suhu alat pengering pakan ikan yang dikendalikan menghasilkan keluaran yang tidak stabil dan sulit untuk mencapai referensi suhu yang diinginkan terlebih jika mendapat gangguan. Oleh karena itu, dibutuhkan kontroler yang dapat mengendalikan suhu dengan stabil untuk menangani permasalahan dalam pengendalian suhu pada kasus alat pengering pakan ikan di Lab FPIK. 
Pada sistem pengendalian suhu, banyak penelitian yang telah dilakukan dalam pengendalian suhu untuk mengontrol keluaran proses dan mengurangi gangguan seperti, Faishol Fathur Riza menggunakan metode kontrol PI untuk mengatur suhu dan monitoring kelembaban pada plant inkubator dengan nilai parameter $\mathrm{Kp}=0,01$ dan $\mathrm{Ki}$ $=0,01$, hasil penelitian tersebut menunjukkan bahwa kontrol PI dapat mempertahankan suhu inkubator dengan stabil mampu mempertahankan suhu referensi [1]. Ahmad Mashuri menggunakan metode kendali logika fuzzy dalam mengendalikan suhu dan mengakuisisi data tingkat kelembaban pada mesin pengering kertas. Penelitian ini memperoleh hasil, sistem pengeringan kertas berbasis kendali logika fuzzy yang dirancang dapat bekerja dengan baik, yaitu diperoleh respons sistem tanpa adanya kesalahan keadaan tunak, baik pada pengujian tanpa beban taupun pengujian dengan beban [2]. Ika Dzikrul Karimah menggunakan kontrol PI $(\mathrm{Kp}=20$ dan $\mathrm{Ti}=117)$ dalam pengendalian suhu pada kasus pengenceran susu bayi dengan metode tuning Ziegler Nichols, hasil dari penelitian tersebut menunjukkan bahwa respons sistem kontrol PI mampu mencapai setting point dengan cukup cepat dan stabil. [3]. Michael Abriyanto P L melakukan penelitian mengenai sistem Supervisory Control And Data Aquisition (SCADA) dalam pengendalian suhu hot room menggunakan metode kontrol Proportional Integral PI dengan nilai parameter $\mathrm{Kp}=115$ dan $\mathrm{Ti}=33$ yang diperoleh melalui tuning Ziegler Nichols 1 hasil dari penelitian tersebut metode kontrol PI kurang stabil dan masih memiliki overshoot [4]. Muhammad Abbie Hamzah melakukan penelitian mengenai perancangan plant alat pembuat sirup buah otomatis dengan kontrol PI sebagai pengendali suhu cairan berbasis Atmega16. Hasil dari penelitian tersebut didapatkan bahwa kontrol PI hasil penalaan dengan metode penalaan Ziegler-Nichols dapat diaplikasikan dengan baik untuk mengendalikan suhu cairan. Dengan metode penalaan tersebut didapatkan parameter kontrol PI yaitu $\mathrm{Kp}=98$ dan $\mathrm{Ti}=132$.[5]. Bhakti Yudho S, dkk menggunakan perbandingan metode kontrol P, PI, dan PID untuk mengendalikan suhu pada boiler, kontroler yang terbaik dari penelitian tersebut adalah kontroler PI karena mampu menghilangan error steady state[6].

Pada penelitian ini dirancang kendali suhu pada purwarupa pengering pakan ikan dengan metode kontrol PI berbasis mikrokontroler. Tujuan dari penelitian ini adalah menerapkan pengendalian suhu pada purwarupa pengering pakan ikan dengan metode kontrol PI berbasis mikrokontroler.

\section{Metode}

\subsection{Perancangan Purwarupa Pengering Pakan Ikan}

Desain mekanik dari purwarupa pengering pakan ikan ini menggunakan bahan kalpanis dengan tebal 1,2 $\mathrm{mm}$. Dimensi mekanik purwarupa perngering pakan ikan, yakni Panjang $45 \mathrm{~cm}$, lebar $45 \mathrm{~cm}$ dan tinggi $42 \mathrm{~cm}$. Alas pada ruang pemanas dibuat lebih tinggi $5 \mathrm{~cm}$ dari dasar dengan tujuan agar panas tidak merambat atau tidak merusak dasar. kotak untuk kipas heater yang berfungsi untuk mempercepat penyebaran udara panas ke dalam ruangan pemanas didesain dengan ukuran panjang $14 \mathrm{~cm}$, lebar $14 \mathrm{~cm}$ dan tinggi $7 \mathrm{~cm}$ sedangkan kotak untuk kipas exhaust yang berfungsi untuk membuang udara panas didalam ruangan pemanas didesain dengan ukuran panjang $14 \mathrm{~cm}$, lebar $14 \mathrm{~cm}$, dan tinggi $4 \mathrm{~cm}$. kotak panel yang berfungsi sebagai tempat meletakkan rangkaian kontrol, didesain dengan ukuran tinggi $25 \mathrm{~cm}$, lebar 25 $\mathrm{cm}$, dan panjang $12 \mathrm{~cm}$. Jarak antara kotak panel dengan ruangan pemanas didesain $2 \mathrm{~cm}$ dengan tujuan agar panas tidak menyebar ke kotak panel. Pada purwarupa pengering pakan ikan ini dipasangkan kaki besi dengan tinggi $20 \mathrm{~cm}$ agar tidak bersentuhan langsung dengan tanah. Gambar 1. menunjukkan desain purwarupa pengering pakan ikan.

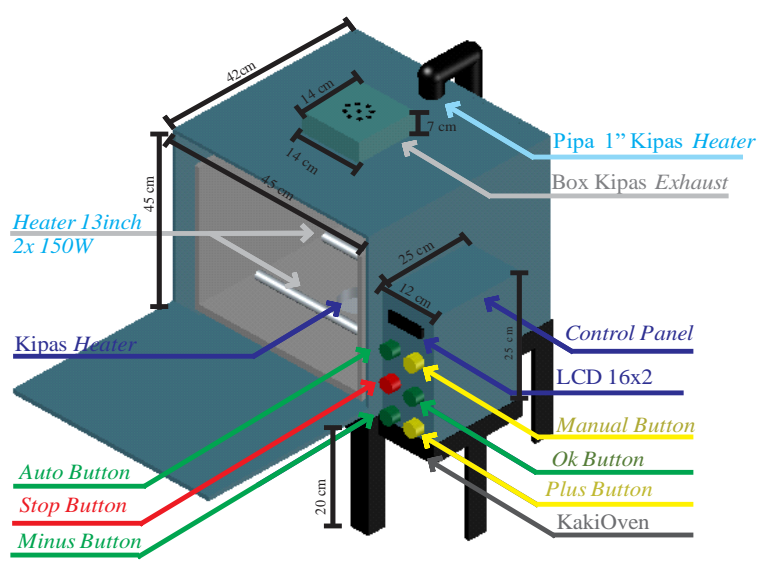

\section{Gambar 1. Desain Purwarupa Pengering Pakan Ikan}

Pada perancangan purwarupa pengering pakan ikan, dikehendaki pengendalian suhu standar pengeringan pakan ikan, yaitu pada range $50^{\circ} \mathrm{C}-60^{\circ} \mathrm{C}[7]$. Proses pengeringan pakan ikan akan selesai jika kadar air yang terkandung pada pakan ikan yang terbaca oleh sensor SEN0193 mencapai 10\% dan kelembaban udara yang terbaca oleh sensor DHT22 mencapai 10\%RH[8].

\subsection{Perancangan Perangkat Keras}

Perangkat keras secara keseluruhan dapat ditunjukkan pada Gambar 2. Perangkat keras dirancang untuk membentuk purwarupa pengering pakan ikan dengan menggunakan metode kontrol PI. 



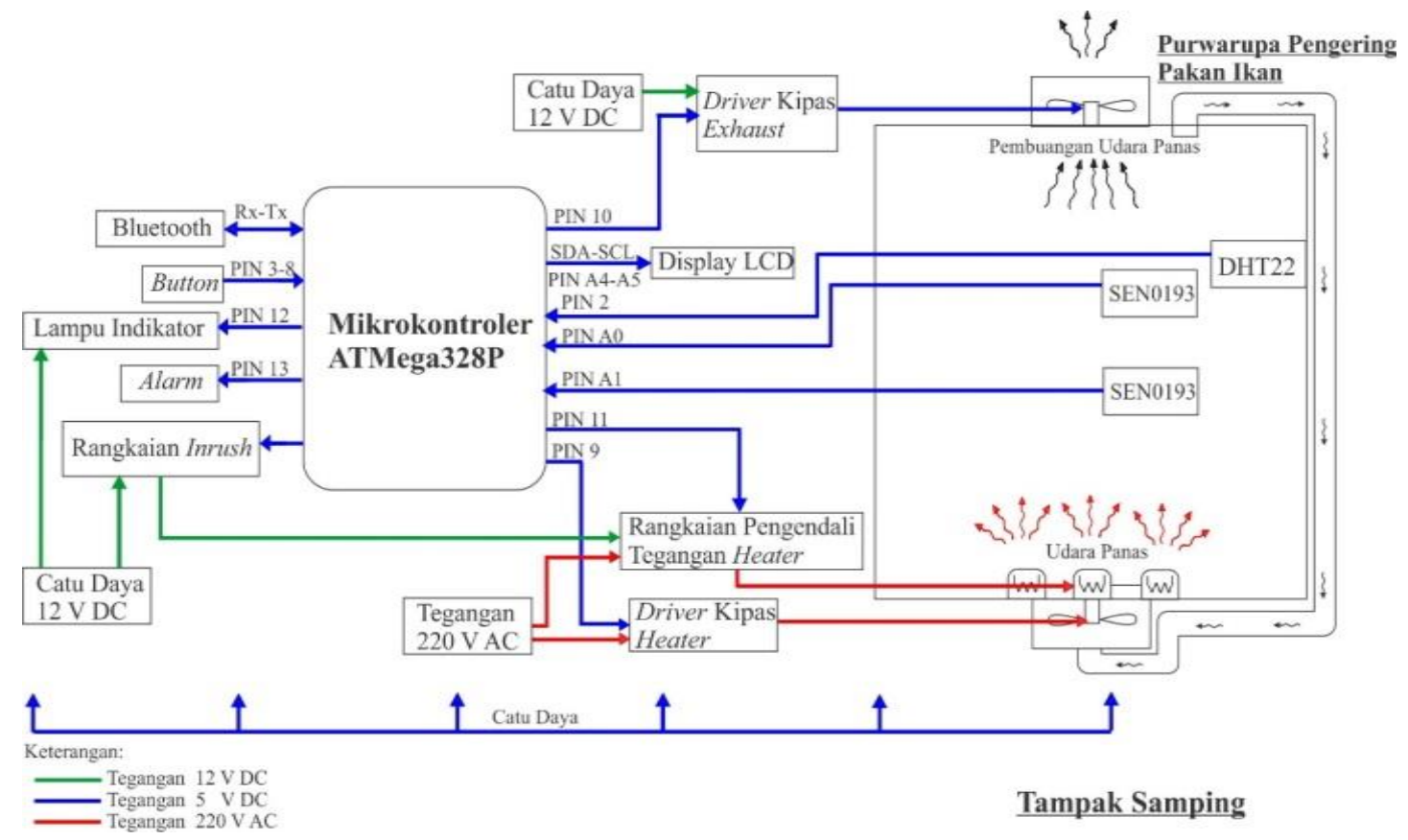

Gambar 2. Blok Diagram Rancangan Hardware Sistem Pengeringan Pakan Ikan

Spesifikasi perancangan perangkat keras dari sistem pengeringan pakan ikan ini terdiri dari:

1. Purwarupa pengering pakan ikan sebagai ruang utama untuk menaruh pakan ikan yang akan dikeringkan. Didalamnya terdiri dari heater, kipas heater, kipas exhaust, sensor DHT22, sensor SEN0193.

2. Heater sebagai sumber energi panas, yang dapat diatur besar kecil panas yang dihasilkan dengan cara diberikan tegangan masukan sesuai sinyal kontrol.
a. Daya : 450 Watt
b. Tegangan : $220 \mathrm{~V}$
c. Arus
: $2,045 \mathrm{~A}$

3. kipas 1 (heater) sebagai penyebar aliran udara pada ruangan pemanas sehingga panas didalam purwarupa pengering pakan ikan akan merata.
a. Daya : $21 \mathrm{Watt}$
b. Tegangan : 220-240 V
c. Frekuensi : $50 \mathrm{~Hz}$
d. Arus : $0.14 \mathrm{~A}$

4. kipas exhaust (keluaran) sebagai pembuangan udara basah (uap).

a. Tegangan : $12 \mathrm{~V}$

b. Arus :0.2 A

5. Catu daya sebagai sumber daya bagi semua komponen yang digunakan.

6. Mikrokontroler ATMega328P digunakan sebagai unit kontroler untuk mengaplikasikan kendali open loop, Kontrol PI, dan mengirim data referensi dan data sensor ke komputer untuk dimonitor. Alokasi masingmasing pin mikrokontroler dapat dibagi berdasarkan fungsinya ditunjukkan pada gambar 3 .

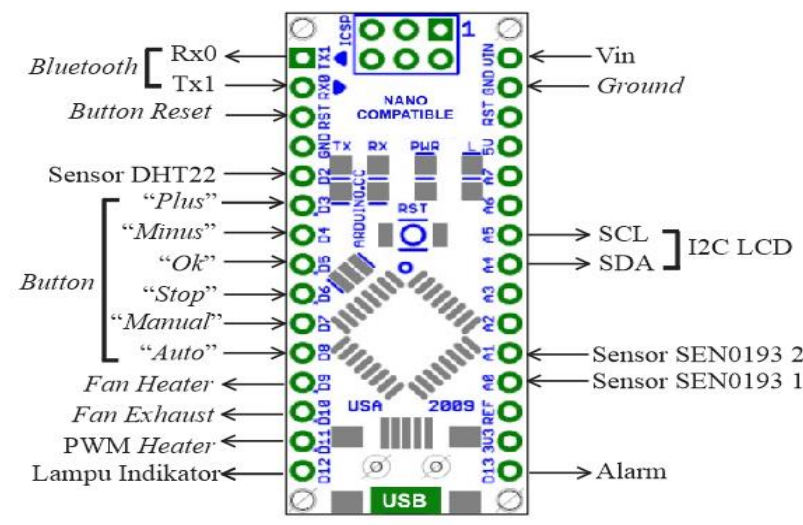

Gambar 3. Diagram Sistem Minimum Atmega328P

7. Rangkaian pengendali tegangan Heater adalah rangkaian yang berfungsi untuk mengendalikan tegangan heater agar panas yang timbul sesuai dengan masukkan.

8. Sensor DHT22 adalah sensor pendeteksi suhu dan kelembaban ruangan pengering pakan ikan, kemudian data suhu dikirim ke mikrokontroler yang akan digunakan sebagai umpan balik dari sistem kendali PI, kemudian datanya ditampilkan ke LCD.

9. Sensor SEN0193 adalah sensor yang digunakan untuk mendeteksi kadar air dari pakan ikan.

10. LCD (liquid crystal display) dan driver I2C LCD berfungsi sebagai media tampilan selama proses pengendalian berlangsung.

11. Button digunakan sebagai pengaturan dan pemilihan menu-menu proses dan pengesetan referensi. 
12. Lampu Indikator berfungsi sebagai penanda bahwa proses pengendalian sedang berjalan atau sudah selesai.

13. Komputer sebagai penampil tanggapan sistem (proses monitoring).

\subsection{Perancangan Perangkat Lunak}

2.3.1. Algoritma dan Diagram Alir Purwarupa Pengering Pakan Ikan

Pada bagian ini terdiri dari algoritma dan diagram alir purwarupa pengering pakan ikan yang ditunjukkan pada Gambar 4. Algoritma perangkat lunak dari purwarupa pengering pakan ikan adalah sebagai berikut :

a. Mulai.

b. Inisialisasi I/O register dan variabel.

c. Deteksi dan inisialisasi sensor DHT22.

d. Tampilan LCD "TUGAS AKHIR PENGERING P. IKAN".

e. Proses off (proses close loop atau open loop tidak dijalankan). f. Proses penentuan mode operasi yang akan dijalankan dengan algoritma sebagai berikut :

- Jika diterima perintah proses auto dari Interface maka lanjutkan ke algoritma g.

- Jika diterima perintah proses manual dari Interface maka lanjutkan ke algoritma j.

- Pemilihan mode operasi melalui tombol pada kotak panel di sistem mikrokontroler Atmega328P. Jika tombol start auto ditekan maka lanjutkan ke algoritma $\mathrm{h}$, jika tombol start manual ditekan maka lanjutkan ke algoritma $\mathrm{k}$.

g. Proses penerimaan data parameter kontrol close loop (setpoint dan parameter kontrol PI) dari Interface.

h. Proses penentuan data parameter kontrol close loop (setpoint) melalui tombol pada kontrol panel oven.

i. Proses close loop.

j. Proses penerimaan data parameter kontrol open loop dari Interface.

k. Proses penentuan data u kontrol open loop melalui tombol pada kontrol panel oven.

1. Proses open loop.

m. Selesai.

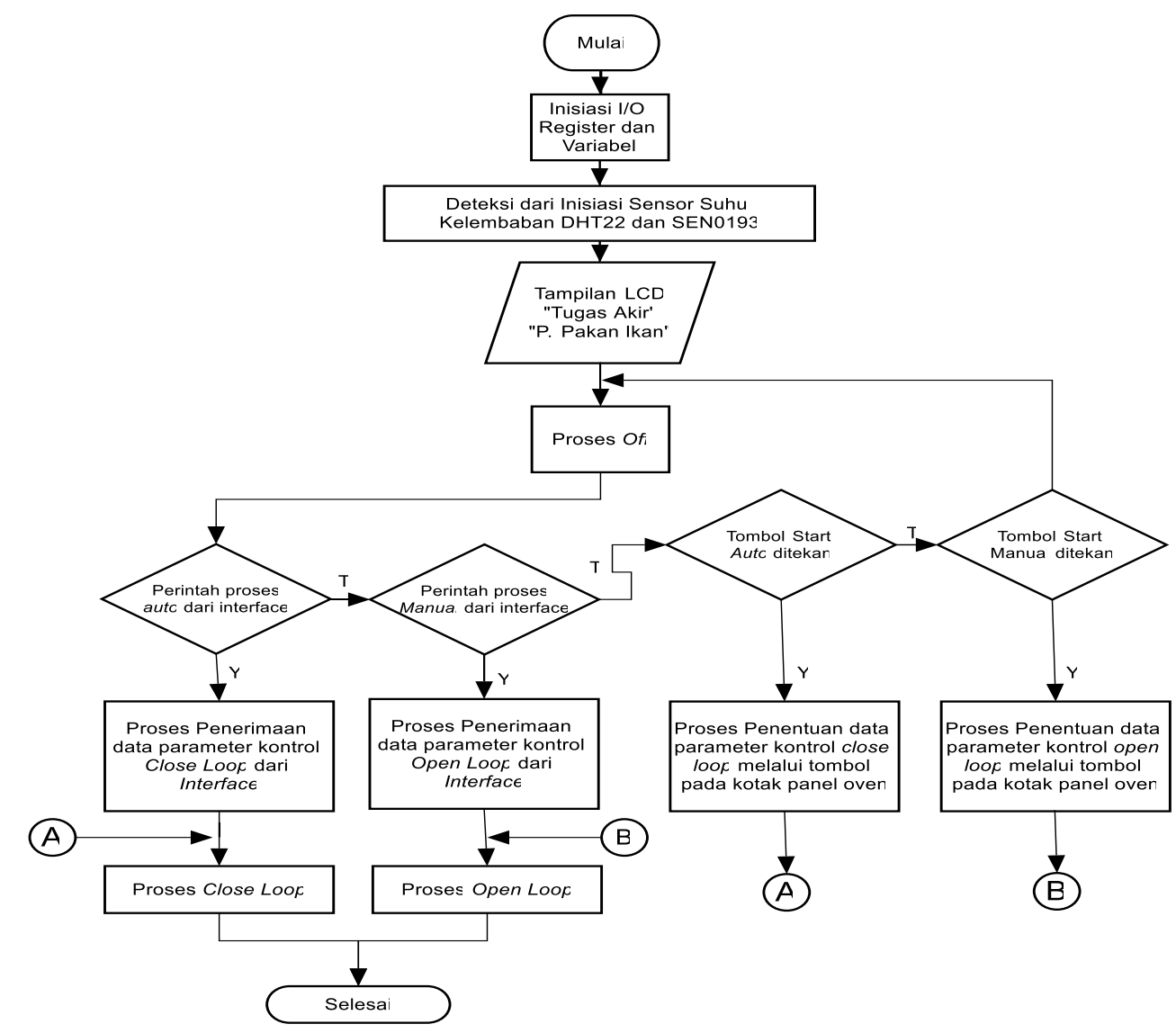

Gambar 4. Diagram Alir Keseluruhan Mikrokontroler Atmega328p

\subsubsection{Perancangan Kontrol PI}

Kontrol PI digunakan untuk mengatur suhu pada purwarupa pengering pakan ikan sesuai dengan referensi yang diinginkan, yaitu antara $50^{\circ} \mathrm{C}$ hingga $60^{\circ} \mathrm{C}$ (sesuai dengan standar dalam pengeringan pakan ikan). Penentuan parameter kontrol PI (Kp dan Ti) dilakukan melalui eksperimen bump test dengan mengirimkan 
perubahan sinyal u (step) secara manual oleh user melalui kotak panel atau Interface. Gambar 5. menunjukkan blok diagram perancangan kontrol PI.

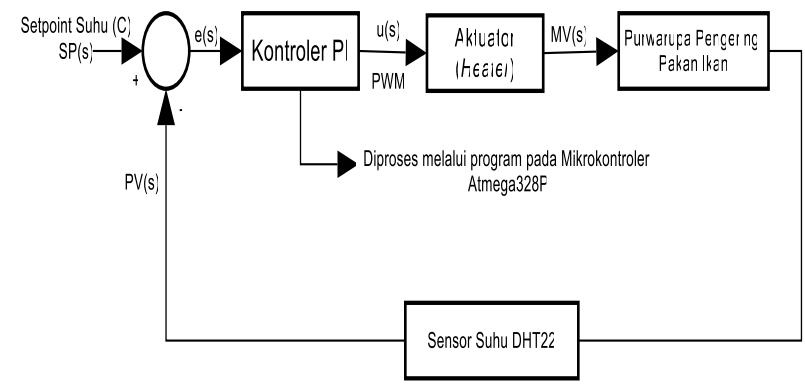

\section{Gambar 5. Diagram Blok Perancangan Kontrol PI}

Eksperimen bump test pada perancangan kontrol PI dilakukan dengan mengirimkan perubahan nilai $\mathrm{u}$ dari $30 \%$ menjadi $40 \%$ melalui Interface. Eksperimen bump test pada perancangan ini dilakukan pada kondisi suhu awal purwarupa pengering pakan ikan $35^{\circ} \mathrm{C}$. Hasil dari eksperimen bump test dengan perubahan u dari $30 \%$ menjadi $40 \%$ ditunjukkan pada Gambar 6 .

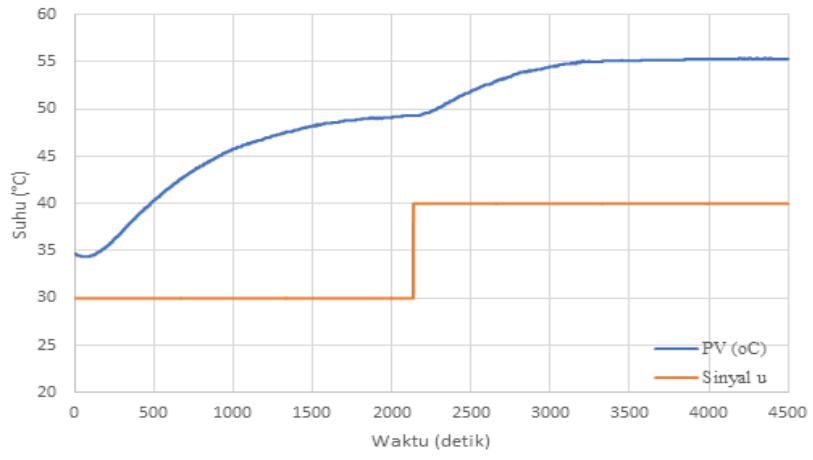

Gambar 6. Hasil Dari Eksperimen Bump Test Dengan Perubahan U Dari 30\% Menjadi 40\%.

Dari Gambar 6. bahwa output proses bersifat stabil (dapat mencapai kondisi steady ketika diberi perubahan nilai u) sehingga model proses yang digunakan merupakan model self regulating atau model FOPDT dengan nilai dari parameter FOPDT berdasarkan pada persamaan (1), (2), dan (3) sebagai berikut :

1. Waktu keterlambatan transportasi (L)

$$
\mathrm{L}=2176 \text { detik }-2136 \text { detik }=40 \text { detik }
$$

2. Waktu proses $(\mathrm{T})$

$$
\begin{aligned}
\Delta P V_{63 \%} & =0,63 * \Delta P V \\
& =0,63 * P V_{1}-P V_{0} \\
\Delta P V_{63 \%} & =P V_{0}+\Delta P V_{63 \%}
\end{aligned}
$$

Sehingga nilai PV 63\% dapat diperoleh melalui perhitungan sebagai berikut:

$$
\begin{aligned}
\Delta P V_{63 \%} & =0,63 *(55-49,3)^{\circ} \mathrm{C} \\
& =0,63 * 5,7{ }^{\circ} \mathrm{C} \\
& =3,591^{\circ} \mathrm{C} \\
\Delta P V_{63 \%} & =49,3^{\circ} \mathrm{C}+3,591^{\circ} \mathrm{C} \\
& =52,891^{\circ} \mathrm{C} \\
\mathrm{T}_{\text {Suhu } 52,891^{\circ} \mathrm{C}} & =2642 \text { detik }-2176 \text { detik } \\
& =466 \text { detik }
\end{aligned}
$$

3. Gain statis proses $(\mathrm{K})$

$$
\begin{aligned}
\mathrm{K} & =\frac{\Delta \mathrm{PV}}{\Delta \mathrm{U}} \\
\mathrm{K} & =\frac{(55-49,3)^{\circ} \mathrm{C}}{(40-30) \%} \\
& =0,57 \frac{{ }^{\circ} \mathrm{C}}{\%}
\end{aligned}
$$

Sehingga model dari purwarupa pengering pakan ikan dapat diperoleh sesuai dengan persamaan model FOPDT adalah

$G(s)=\frac{0,57}{466 s+1} \cdot e^{-40 s}$

Berdasarkan ketiga parameter FOPDT yang diperoleh, dapat ditentukan nilai dari parameter kontrol PI menggunakan metode Ziegler Nichols 1 sebagai berikut :

$$
\begin{aligned}
K p & =\frac{0,9 \cdot T}{K \cdot L} \\
& =\frac{0,9 \times 466}{0,57 \times 40} \\
& =18,4 \\
T i & =3,33 \times L \\
& =3,33 \times 40 \\
& =133,2
\end{aligned}
$$

\section{Hasil dan Analisis \\ 3.1. Pengujian Perangkat Keras \\ 3.1.1. Pengujian Sensor DHT22}

Pengujian pembacaan sensor DHT22 dilakukan dengan membandingkan pembacaan suhu dan kelembaban antara sensor DHT22 dengan higrometer digital. Hasil pengujian sensor suhu DHT22 ditunjukkan pada Tabel 1 dan hasil pengujian kelembaban DHT22 ditunjukkan pada Tabel 2.

Tabel 1. Pengujian Sensor Suhu DHT22

\begin{tabular}{cccc}
\hline No. & $\begin{array}{c}\text { Sensor Suhu DHT22 } \\
\left({ }^{\circ} \mathrm{C}\right)\end{array}$ & Suhu Higrometer $\left({ }^{\circ} \mathrm{C}\right)$ & $\mid$ Error| $\left({ }^{\circ} \mathrm{C}\right)$ \\
\hline 1 & 30 & 30,1 & 0,1 \\
2 & 35 & 35 & 0 \\
3 & 40 & 39,9 & 0,1 \\
4 & 45 & 45 & 0 \\
5 & 50 & 50 & 0 \\
6 & 55 & 55,1 & 0,1 \\
& Rata-rata error & & 0,05 \\
\hline
\end{tabular}


Berdasarkan hasil pengujian sensor suhu DHT22 pada Tabel 1 dapat dilihat bahwa pembacaan suhu oleh sensor DHT22 cukup akurat dengan rata-rata error pembacaan suhu adalah $0,05^{\circ} \mathrm{C}$.

Tabel 2. Pengujian Sensor Kelembaban DHT22

\begin{tabular}{cccc}
\hline No. & $\begin{array}{c}\text { Sensor Kelembaban } \\
\text { Udara DHT22 }(\% \mathrm{RH})\end{array}$ & $\begin{array}{c}\text { Kelembaban Udara } \\
\text { Higrometer }(\% \mathrm{RH})\end{array}$ & $\begin{array}{c}\mid \text { Error } \\
(\% \mathrm{RH})\end{array}$ \\
\hline 1 & 10,8 & 10 & 0,8 \\
2 & 21,7 & 21 & 0,7 \\
3 & 31 & 30 & 1 \\
4 & 40 & 40 & 0 \\
5 & 50 & 50 & 0 \\
& Rata-rata error & & 0,5 \\
\hline
\end{tabular}

Berdasarkan hasil pengujian sensor kelembaban DHT22 pada Tabel 2 dapat dilihat bahwa pembacaan kelembaban oleh sensor DHT22 cukup akurat dengan rata-rata error pembacaan kelembaban adalah $0,5 \%$ RH.

\subsubsection{Pengujian Sensor SEN0193}

Pengujian nilai keluaran sensor SEN0193 dilakukan dengan memberikan variasi terhadap kadar air dalam pakan ikan. Nilai variasi dari 10\% hingga 50\%. Hasil pengambilan data disajikan pada Tabel 3 .

Tabel 3. Hasil Pengujian Sensor SEN0193

\begin{tabular}{cccccc}
\hline NO & $\begin{array}{c}\text { Massa } \\
\text { Pakan } \\
\text { lkan } \\
(\mathrm{gr})\end{array}$ & $\begin{array}{c}\text { Massa } \\
\text { Air } \\
(\mathrm{gr})\end{array}$ & $\begin{array}{c}\text { Kadar Air } \\
\text { Hitung } \\
(\%)\end{array}$ & $\begin{array}{c}\text { Kadar Air } \\
\text { Sensor } \\
(\%)\end{array}$ & Error \\
\hline 1 & 45 & 5 & 10 & 10,053 & 0,053 \\
2 & 40 & 10 & 20 & 20,03 & 0,03 \\
3 & 35 & 15 & 30 & 30,08 & 0,08 \\
4 & 30 & 20 & 40 & 39,93 & 0,063 \\
5 & 25 & 25 & 50 & 50,05 & 0,05 \\
& \multicolumn{5}{c}{ Error rata-rata } \\
\hline
\end{tabular}

Berdasarkan hasil pengujian sensor SEN0193 yang ditunjukkan pada Tabel 1 dapat dilihat bahwa pembacaan kadar air oleh sensor SEN0193 cukup baik dengan ratarata error pembacaan kadar air adalah $0,055 \%$.

\subsection{Pengujian Respons Sistem \\ 3.2.1. Pengujian Respons Sistem dengan Referensi Tetap}

Pengujian respons sistem dengan referensi tetap dilakukan dengan mengirimkan referensi suhu sebesar $55^{\circ} \mathrm{C}$ melalui Interface. Pengujian ini dilakukan pada kondisi suhu awal purwarupa pengering pakan ikan $31^{\circ} \mathrm{C}$. Respons yang dihasilkan sistem dengan referensi tetap ditunjukkan pada Gambar 7.

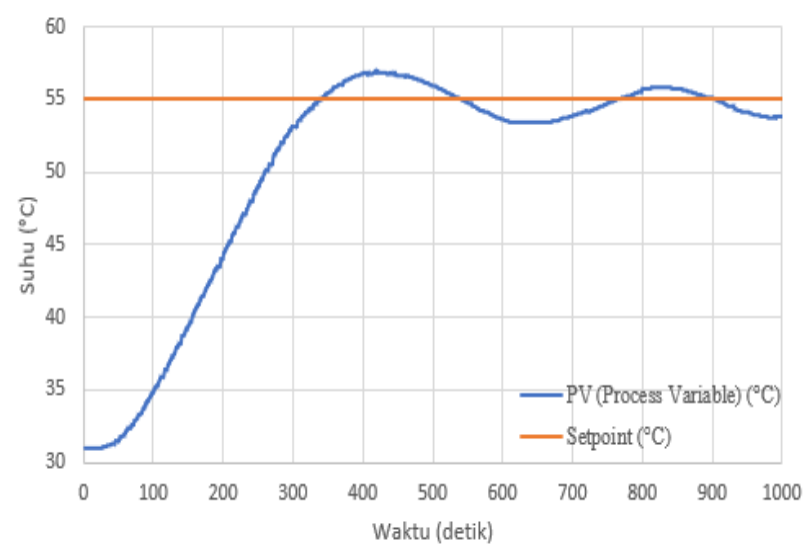

Gambar 7. Hasil Pengujian Respons Sistem dengan Referensi Tetap.

Berdasarkan hasil respons sistem pada referensi tetap pada Gambar 7. dapat dilihat bahwa kontrol PI mampu mencapai dan mempertahankan output suhu sesuai dengan referensi $55^{\circ} \mathrm{C}$ dengan tanggapan respons transien untuk waktu tunda (Td) sebesar 186 detik, waktu naik (Tr) sebesar 339 detik, waktu puncak (Tp) sebesar 417 detik, waktu penetapan (Ts) sebesar 583 detik, dan maximum overshoot $(\mathrm{Mp})$ sebesar $3,45 \%\left(1,9^{\circ} \mathrm{C}\right)$.

\subsubsection{Pengujian Respons Sistem dengan Referensi Naik}

Pengujian respons sistem dengan referensi naik dilakukan dengan mengubah referensi suhu dari $55^{\circ} \mathrm{C}$ naik menjadi $57^{\circ} \mathrm{C}$ dengan kondisi suhu awal pada purwarupa pengering pakan ikan adalah $55^{\circ} \mathrm{C}$. Pengujian ini dilakukan untuk mengetahui kemampuan kontrol PI dalam menanggapi kenaikan referensi suhu. Hasil pengujian respons sistem dengan referensi naik ditunjukkan pada Gambar 8.

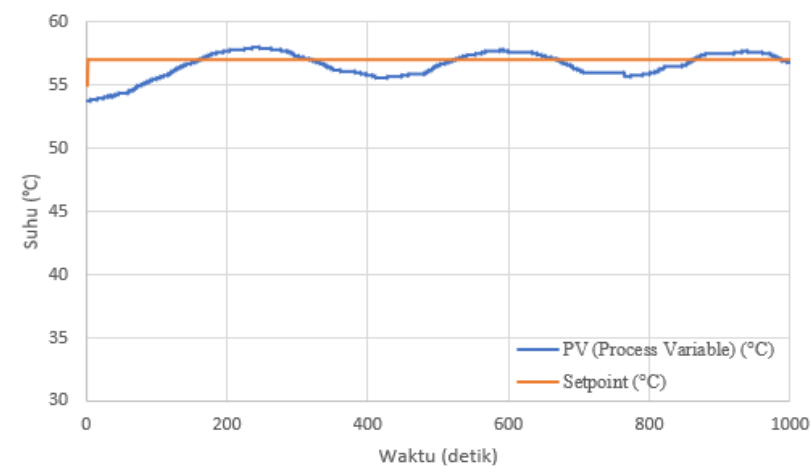

Gambar 8. Hasil Pengujian Respons Sistem dengan Referensi Naik

Berdasarkan hasil respons sistem pada referensi naik pada Gambar 8 dapat dilihat bahwa kontrol PI mampu mencapai dan mempertahankan output suhu sesuai dengan kenaikan referensi suhu menjadi $57^{\circ} \mathrm{C}$ dengan 
tanggapan respons transien untuk Td sebesar 101 detik, Tr sebesar 169 detik, Tp sebesar 247 detik, Ts sebesar 469 detik, dan Mp yang dihasilkan adalah $1,75 \%\left(1^{\circ} \mathrm{C}\right)$.

\subsubsection{Pengujian Respons Sistem dengan Referensi Turun}

Pengujian respons sistem dengan referensi turun dilakukan dengan mengubah referensi suhu dari $57^{\circ} \mathrm{C}$ turun menjadi $53^{\circ} \mathrm{C}$. dengan kondisi suhu awal pada purwarupa pengering pakan ikan adalah $57^{\circ} \mathrm{C}$ Pengujian ini dilakukan untuk mengetahui kemampuan kontrol PI dalam menanggapi penurunan referensi suhu. Hasil pengujian respons sistem dengan referensi turun ditunjukkan pada Gambar 9.

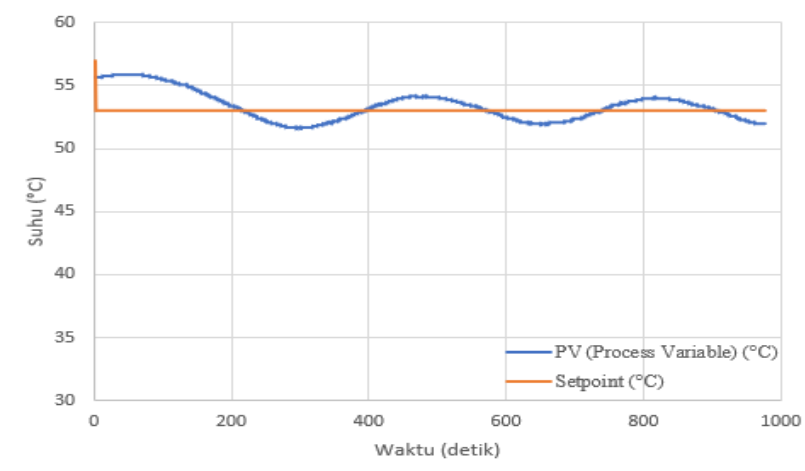

Gambar 9. Hasil Pengujian Respons Sistem dengan Referensi Turun

Berdasarkan hasil respons sistem pada referensi naik pada Gambar 9. dapat dilihat bahwa kontrol PI mampu mencapai dan mempertahankan output suhu sesuai dengan penurunan referensi menjadi $53^{\circ} \mathrm{C}$ dengan tanggapan respons transien untuk Td sebesar 162 detik, $\mathrm{Tr}$ sebesar 214 detik, Tp sebesar 278 detik, Ts sebesar 448 detik, dan Mp yang dihasilkan adalah 3,2\% $\left(-1,7^{\circ} \mathrm{C}\right)$.

\subsubsection{Pengujian Respon Sistem dengan Gangguan}

Pengujian respons sistem dengan gangguan dilakukan dengan membuka pintu purwarupa pengering pakan ikan selama 13 menit ketika sistem telah mencapai keadaan stabil. Pengujian ini dilakukan untuk mengetahui kemampuan kontrol PI dalam merespons gangguan tersebut. Pengujian ini dilakukan pada kondisi referensi suhu yang diberikan adalah $55^{\circ} \mathrm{C}$, suhu purwarupa pengering pakan ikan sebelum diberi gangguan adalah stabil pada suhu $55^{\circ} \mathrm{C}$. Hasil pengujian respons sistem dengan gangguan ditunjukkan pada Gambar 10.

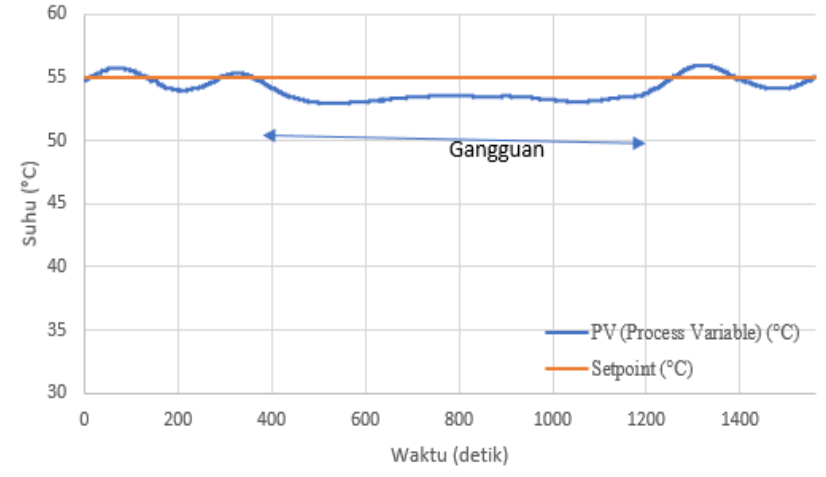

Gambar 10. Hasil pengujian Respon Sistem dengan Gangguan

Berdasarkan hasil respons sistem dengan gangguan pada Gambar 10 dapat dilihat bahwa gangguan diberikan pada detik ke-373 selama kurang lebih 13 menit. Pemberian gangguan membuat respons sistem menjadi tidak stabil dan suhu menurun cukup jauh dari referensi $55^{\circ} \mathrm{C}$ dengan suhu terendah yang tercapai adalah $52,9^{\circ} \mathrm{C}$, akan tetapi suhu tidak terus menurun pada detik ke-566 suhu mulai berangsur naik hingga suhu tertinggi $53,5^{\circ} \mathrm{C}$ tetapi sistem tetap tidak dapat mencapai referensi suhu $55^{\circ} \mathrm{C}$ dan masih tidak stabil, kemudian pada detik ke-1154 pintu purwarupa pengering pakan ikan kembali ditutup dan suhu mulai berangsur naik untuk mencapai referensi yang diberikan. Dari hasil pengujian respons sistem dengan gangguan dapat disimpulkan bahwa kontrol PI mampu bekerja dengan baik dalam menanggapi gangguan yang diberikan sehingga gangguan dapat dikurangi dan dapat mengembalikan respons sistem ke referensi $55^{\circ} \mathrm{C}$ ketika pintu purwarupa pengering pakan ikan ditutup dengan waktu pemulihan menuju keadaan stabil adalah 300 detik.

\subsubsection{Pengujian Perbandingan Metode Kontrol PI (Proportional Integral) dan Metode Kontrol On-Off.}

Pengujian perbandingan Kontroler dilakukan dengan membandingkan respons keluaran sistem metode kontrol PI dan metode kontrol On-off. Suhu awal metode kontrol PI adalah 35 dan suhu awal metode kontrol on-off adalah 35. Hasil perbandingan pengujian metode kontrol Proportional - Integral (PI), Kontrol On-off ditunjukan pada Gambar 11. 


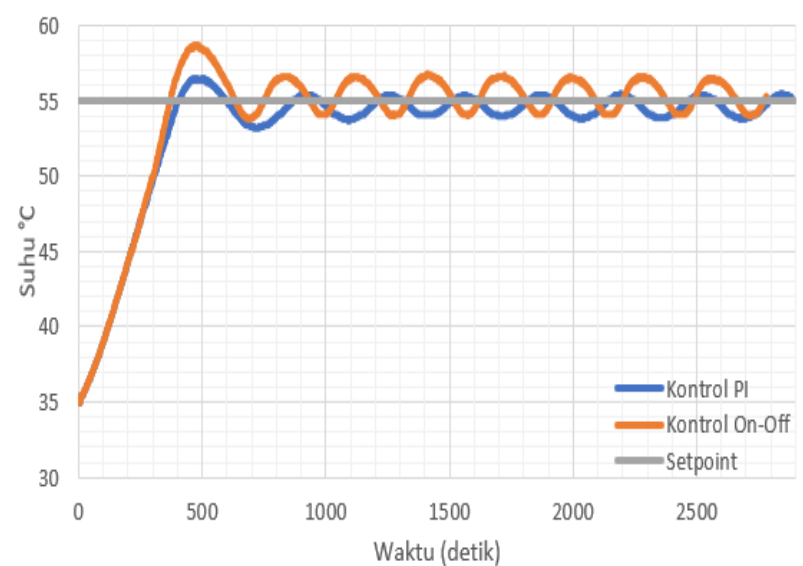

Gambar 11. Hasil Pengujian Perbandingan Respons Keluaran Sistem Metode Kontrol PI dan On-Off

Berdasarkan hasil respons keluaran sistem metode kontrol PI dan metode kontrol on-off dapat disusun pada Tabel 4.

Tabel 4. Perbandingan Nilai Respons Transien

\begin{tabular}{cccccc}
\hline Metode & $\mathrm{Td}(\mathrm{s})$ & $\mathrm{Tr}(\mathrm{s})$ & $\mathrm{Tp}(\mathrm{s})$ & $\mathrm{Ts}(\mathrm{s})$ & $\mathrm{Mp}(\%)$ \\
\hline $\mathrm{PI}$ & 208 & 399 & 472 & 794 & 2,72 \\
On-Off & 210 & 355 & 452 & - & 9,09 \\
\hline
\end{tabular}

Berdasarkan hasil pengujian perbandingan nilai respons transien pada Tabel 4 dapat dilihat bahwa metode kontrol PI memiliki kelebihan dibandingkan dengan metode kontrol on-off, yaitu memiliki waktu tunda (Td), waktu penetapan (Ts), dan nilai maximum overshoot $(\mathrm{Mp})$ lebih kecil dibandingkan dengan metode kontrol On-off sedangkan kontrol on-off memiliki waktu puncak (Tp) dan waktu naik (Tr) lebih kecil dibandingkan dengan kontrol PI. Dapat diambil kesimpulan bahwa secara keseluruhan metode kontrol PI lebih banyak kelebihan dibandingkan dengan metode kontrol On-off. Sehingga metode kontrol PI sangat cocok untuk menggantikan kontrol On-off dalam hal mengendalikan purwarupa pengering pakan ikan.

\section{Kesimpulan}

Berdasarkan hasil dan analisis yang telah dilakukan, maka dapat dibuat kesimpulan perancangan kendali suhu pada purwarupa pengering pakan ikan menggunakan metode kontrol PI (Proportional Integral) berbasis mikrokontroler telah berhasil direalisasikan menggunakan mikrokontroler Atmega328P yang dapat mengendalikan suhu dari purwarupa pengering pakan ikan dengan mempertimbangkan waktu pengeringan berdasarkan kelembaban udara dan kadar air dari pakan ikan. Pada pengujian sensor suhu dan kelembaban DHT22 dihasilkan rata-rata error pembacaan suhu sebesar $0,05^{\circ} \mathrm{C}$ dan rata-rata error pembacaan kelembaban sebesar 0,5\%RH. Pada pengujian sensor kadar air SEN0193 dihasilkan rata-rata error pembacaan kadar air sebesar
$0,055 \%$. Pada pengujian respons sistem dengan referensi tetap, metode kontrol PI menghasilkan Td sebesar 186 detik, Tr sebesar 339 detik, Tp sebesar 417 detik, Ts sebesar 583 detik, Mp adalah sebesar 3,45\% $\left(1,9^{\circ} \mathrm{C}\right)$. Pada pengujian respons sistem dengan referensi naik, metode kontrol PI menghasilkan Td sebesar 101 detik, Tr sebesar 169 detik, Tp sebesar 247, Ts sebesar 469 detik dan $\mathrm{Mp}$ sebesar $1,75 \%\left(1^{\circ} \mathrm{C}\right)$. Pada pengujian respons sistem dengan referensi turun, metode kontrol PI menghasilkan Td sebesar 162 detik, Tr sebesar 214 detik, Tp sebesar 278 detik, Ts sebesar 448 detik, Mp adalah sebesar $3,2 \%\left(-1,7^{\circ} \mathrm{C}\right)$. Dari hasil pengujian perbandingan metode kontrol PI dan On-off, secara keseluruhan metode kontrol PI lebih baik dibandingkan dengan kontrol On-off.

\section{Referensi}

[1] F. F. Riza, I. Setiawan, and Sumardi, "Perancangan Sistem Pengendali Suhu dan Memonitoring Kelembaban Berbasis Atmega8535 pada Plant Inkubator," 2011.

[2] A. Mashuri, "Perancangan sistem pengendalian suhu dan Akuisisi data tingkat kelembaban pada Mesin pengering kertas berbasis Kendali logika fuzzy," 2008.

[3] I. Dzikrul, “Aplikasi Kendali Proporsional Integral Pada Sistem Pengontrolan Suhu Studi Kasus Pengencer Susu Bayi Otomatis," no. September, 2012.

[4] M. A. Limantara, "Perancangan Sistem Supervisory Control And Data Acquisition (SCADA) dalam Pengendalian Suhu Pada Prototype Hot Room," 2017.

[5] M. A. Hamzah and B. Setiyono, "Perancangan Plant Alat Pembuat Sirup Buah Otomatis Dengan Kontrol PI Sebagai Pengendali Suhu Cairan Berbasis Atmega16."

[6] B. Y. S, H. Hikmarika, and S. Dwijayanti, "Aplikasi Perbandingan Pengendali P, PI , Dan PID Pada Proses Pengendalian Suhu Dalam Sistem Mini Boiler," vol. 3, no. 2, pp. 12-18, 2013.

[7] Subandiyono,"Modul Praktikum Mata Kuliah Nutrisi Ikan". 2016.

[8] W. T. Handoyo and L. Assadad, "Karakterisasi Proses Produksi Dan Kualitas Tepung Ikan Di Beberapa Pengolah Skala Kecil," Semin. Nas. Tah. XIII Has. Penelit. Perikan. dan Kelautan., pp. 197206, 2016. 